\title{
Proteasome Function Inhibition
}

National Cancer Institute

\section{Source}

National Cancer Institute. Proteasome Function Inhibition. NCI Thesaurus. Code C41597.

Proteasome Inhibition involves interference with, or restraint of, the activities of macromolecular multicatalytic cellular structures in the cytosol and nucleus with multiple proteolytic activities involved in AT P-dependent ubiquitinated protein degradation and antigen processing. 